RUNNING HEAD: GROUNDING SOCIAL EMBODIMENT

\title{
Grounding Social Embodiment
}

\author{
Daniël Lakens
}

Eindhoven University of Technology

Word Count: 5585

In Press, Social Cognition

Keywords: Embodiment, Conceptual Metaphor Theory, Perceptual Symbol Systems, Associated Systems Theory, Inferences.

Author Note: I would like to thank Nils Jostmann and Thomas Schubert for feedback on a previous draft of this article.

Correspondence can be addressed to Daniël Lakens, Human Technology Interaction Group, IPO 1.33, PO Box 513, 5600MB Eindhoven, The Netherlands. E-mail: D.Lakens@tue.nl. 


\begin{abstract}
Social embodiment research examines how thoughts, affect, and behavior is influenced by sensory, motor, and perceptual cues in the environment. It has repeatedly received criticism due to a focus on demonstration studies. Here, I aim to identify some of the possible reasons underlying the lack of theoretical progress. First, I warn against relying too strongly on inductive inferences due to the weak empirical support for social embodiment findings. Second, I will discuss two dominant theoretical frameworks in social embodiment research (conceptual metaphor theory and perceptual symbol systems theory) in light of their potential to inspire empirically testable hypotheses. Finally, I propose that one way to turn social embodiment research into a progressive research line is to integrate it more firmly with past theoretical work in social cognition, and focus on understanding the contexts in which concrete cues in the environment are salient and accessible enough to influence social inferences.
\end{abstract}

Word Count: 149 


\section{Grounding Social Embodiment}

If we wish to attribute the greatest known reality to the material world which exists immediately only in our idea, we give it the reality which our own body has for each of us; for that is the most real thing for everyone.

Schopenhauer, WWR 1105.

Sensory experiences are an important source of meaning. In recent years, researchers have examined the interrelated nature of sensory experiences, affect, behavior, and cognition in a very productive line of research, broadly referred to as embodiment. Concepts are considered embodied when thoughts about the meaning of mental structures depend on activity in systems also used for perception, action, and emotion (e.g., Glenberg, DeVega, \& Graesser, 2008). Social embodiment (Barsalou, Niedenthal, Barbey, \& Ruppert, 2003) is a sub discipline of embodiment research that focusses on how people process social information. This research area builds on the idea that social inference processes involved in thoughts about the meanings of entities and events are influenced by sensory, motor, and perceptual cues in the environment.

It is in the context of early work on social inferences that the term 'social priming' originated (see Salancik \& Pfeffer, 1978, Smith, 1984), where semantic cues can activate associated concepts, which influence subsequent thoughts about social information. Researchers have drawn an analogy between the way people process social information and how a computer processes information, where 'input' is stored in memory and translated into 'machine language' so that a central processor can operate upon the input, which is then translated back into output understandable by the user (see Wyer, 1974). Social embodiment 
takes a stance against this computer metaphor, and proposes that conceptual thought depends upon sensorimotor information, either through conceptual metaphors (Lakoff \& Johnson, 1999), or neural reactivation of sensorimotor information (Barsalou, 1999). Embodied conceptual structures have been argued to play an important role in social priming effects (Bargh, 2006).

The idea that mental representations of social concepts (e.g., hostile) contain sensory and affective information in addition to semantic meaning has never been questioned in social cognition research (e.g., Wyer \& Srull, 1986). As Fodor (1985) notes: "No one in his right mind doubts that perception interacts with cognition somewhere. What's at issue [...] is the locus of this interaction.” Social embodiment distinguishes itself from earlier work on social priming by lowering the level at which perception and cognition interact. In the work of Wyer and Srull (1986), both semantic bins (the mental dictionary) as referent bins (which can consist of visual images, episodic memories, or subjective affective responses) exist, but incoming information is first encoded into semantic concepts. Social embodiment, on the other hand, starts from the viewpoint that such a translation process is unnecessary and that sensory, motor, and affective neural states are re-activated during cognitive processes.

Reviews of embodiment research in social psychology show that embodiment effects go back at least half a century (see Barsalou et al., 2003; Meier, Schnall, Schwarz, \& Bargh, 2012). In this article I use the term social embodiment to refer to research that is most closely aligned with the social priming research that emerged from work on social inferences (e.g., Srull \& Wyer, 1979). There has been some debate about whether 'social embodiment' or 'social priming' is a meaningful concept, and how it should be defined (see Molden, this issue). Here, I follow previous theoretical work that distinguishes between non-social and social information processing (e.g., Smith, 1984; Wyer \& Srull, 1986). Of central importance in social information processing is how prior attitudes and goals influence social inferences 
about person impressions, judgments, affective reactions, and behaviors, whereas these types of inferences are typically ignored in cognitive models of information processing.

Social embodiment research has examined, among other things, how concrete cues such as warmth, smells, weight, brightness, roughness, elevation, body posture, or motor movements influence person perception, moral judgments, pro-social decisions, attitudes, the desirability of products, emotional states, and behaviors. It is a line of research that has repeatedly received criticism due to a focus on demonstration studies and a lack of theoretically progressive experiments (e.g., Barsalou, 2010; Meier, Schnall, Schwarz, \& Bargh, 2012; Schubert \& Semin, 2009; Zwaan, 2009). Here, I will try to identify some of the reasons for this lack of theoretical progress. First, I discuss the possibility that the current empirical knowledge base in social embodiment is not strong enough to draw reliable inductive inferences. Second, I will discuss two of the dominant theoretical frameworks in social embodiment research, conceptual metaphor theory and perceptual symbol systems theory, in light of their potential to inspire empirically testable predictions. Finally, I suggest that if we want to turn social embodiment research into a progressive research line, we need to understand the contexts in which concrete cues in the environment are salient and accessible enough to influence social inferences.

\section{A Critical Look at the Empirical Data}

As an example of how social information processing is influenced by sensory experiences, consider the finding that the physical experience of weight (manipulated by asking participants to hold either a heavy of light clipboard while filling out a questionnaire) influenced the inferred importance of issues, such as being heard in a decision making procedure (Jostmann, Lakens, \& Schubert, 2009). This study is typical for many findings in the social embodiment literature in that 1) a sensorimotor experience influences 2) social 
inference processes in an unrelated and often more abstract domain 3) seemingly automatically and without awareness of the individual.

Reviews of the social embodiment literature often summarize a wide range of research areas such as facial feedback (e.g., Strack, Martin, \& Stepper, 1988), cross-modal stimulus response congruency effects (e.g., Meier \& Robinson, 2004; Schubert, 2005; Lakens, 2012), and approach avoidance effects (e.g., Rotteveel \& Phaf, 2004; Eder \& Rothermund, 2008). When we turn to research that examines whether sensorimotor information influences social inferences, there are some reasons to worry about the robustness of the empirical knowledge base. Many replication studies of social embodiment effects have failed to provide support for the original hypotheses (e.g., Brandt, IJzerman, \& Blanken, 2014; Earp, Everett, Madva, \& Hamlin, in press; Johnson, Cheung, \& Donnellan; 2014; LeBel \& Campbell, 2013; LeBel \& Wilbur, 2013; Lynott et al., 2014; Pashler, Coburn, \& Harris, 2012). Although there might be specific reasons the hypotheses were not supported in each of these replication studies, a parsimonious explanation for such failures to replicate the original effects is that the original studies were Type 1 errors, and the null-hypothesis is true.

Due to a combination of low statistical power, publication bias, and flexibility during data analysis, the number of false positives in the literature can be much greater than desired (e.g., Dijksterhuis, Van Knippenberg, \& Holland, this issue; Ioannides, 2005). Using p-curve analysis we can examine whether the distribution of $p$-values below .05 in published research is uniformly distributed, which implies the null-hypothesis is true, or whether the distribution is right-skewed (with more $p$-value between .00 and .01 than between .04 and .05 ) as which implies the alternative hypothesis is true (Simonsohn, Nelson, Simmons, 2013). Lakens (2014) performed a p-curve analyses on social embodiment findings reviewed by Meier, Schnall, Schwarz, and Bargh (2012) that examined social inferences. These analyses 
indicated that the social inference studies discussed in this review, taken together, lack evidential value. The findings are more likely to represent chance findings from a selection of tests from a selection of studies, than a robust and reliably observed phenomenon, despite the fact that most of the reported results were statistically significant.

The reason for this lack of evidential value is that practically all studies that have examined social embodiment effects had very small sample sizes and were severely underpowered. The informational value of underpowered studies is very low, and significant published results from underpowered studies are relatively likely to be false positives (Ioannides, 2005; Lakens \& Evers, 2014). Although the idea that concrete cues in the environment influence social inferences might be correct, the empirical observations we have collected so far do not yet provide strong support for this idea. Because of the low informational value of the published research, inductive reasoning based on observed findings is less likely to turn social embodiment into a progressive research line than deductive reasoning. Instead of drawing inspiration from published research, we need theoretical work that allows researchers to make strong and empirically testable predictions. We then need to examine these predictions in larger samples, preferably using pre-registered designs (e.g., Nosek \& Lakens, 2014).

\section{A Critical Look at the Theoretical Frameworks}

Two theories dominate the recent literature in social embodiment: Conceptual Metaphor Theory (CMT; Lakoff \& Johnson, 1999) and Perceptual Symbol Systems (PSS; Barsalou, 1999). I will briefly discuss both these theories, with a special focus on their potential to allow researchers to draw strong predictions about how concrete cues influence social inferences.

Conceptual Metaphor Theory. 
It has been suggested that metaphors embody conceptual meaning (e.g., Richards, 1936; Whitney, 1875). According to Lakoff and Johnson (1999, p. 20) 'An embodied concept is a neural structure that is actually part of, or makes use of, the sensorimotor system of our brains.' The cognitive mechanism that underlies embodied meaning is conceptual metaphor, where concrete source domains are used to think about more abstract target domains. It is assumed that through experiential co-occurrence (e.g., feeling happy and having an upright posture), neural associations are formed through which children learn primary metaphors (e.g., 'happy is up’). These primary metaphors are used in reasoning, mostly unconsciously and automatically (Lakoff, 2012). Conceptual metaphor theory (and later theoretical work such as the neural theory of thought and language) has inspired many researchers in the field of social embodiment, and some researchers have argued for a metaphor-enriched perspective on social cognition (e.g., Landau, Meier, \& Keefer, 2010). I am less optimistic about the potential of such a perspective on social cognition, and believe the use of conceptual metaphors as a theoretical guide in social embodiment is one of the major reasons we are now facing a degenerative research program.

First, as has been argued repeatedly, conceptual metaphor theory lacks a description of possible psychological process models (Boroditsky, 2000; McGlone, 2007; 2011; Murphy, 1996; Schubert, Waldzus, \& Seibt, 2011). This makes it difficult to deduce clearly defined novel predictions about when metaphors are used, which metaphors are used, and how metaphors influence social inferences. The discussion about these questions continues in linguistics (e.g., Gibbs, 2011; McGlone, 2011) but is rarely referred to in articles on social embodiment. Because the underlying mechanisms of conceptual metaphors are not defined apriori, conceptual metaphors can provide post-hoc explanations of almost any empirical finding that shows a relation between sensorimotor cues and social inferences, but it does not allow for strong inferences (Platt, 1964). 
Furthermore, the predictions that can be derived from conceptual metaphors can also be derived from more general cognitive theories. A prediction that has received quite some attention concerns the asymmetry between concrete source domains and more abstract target domains (Lakoff, 2008), where 'results of inferences flow in one direction only, from the sensorimotor domain to the domain of subjective judgment' (Lakoff \& Johnson, 1999, p. 56). However, similar predictions about asymmetric associations are made in non-metaphorical models of associative thought. For example, the fan effect (Anderson, 1974) can explain how asymmetric associations emerge because frequently encountered concepts activate many associated concepts, whereas less frequently encountered concepts activate only a few associated concepts. As a consequence, less frequently encountered concepts (e.g., burden) are more strongly associated with frequently encountered concepts (e.g., weight) than vice versa. Furthermore, automatic translations between domains are more likely to develop for frequently encountered concepts than for less frequently encountered concepts. Because concrete concepts are typically encountered more frequently than abstract concepts, Carlston (1994, p. 38) predicts in his associative systems theory (see below) that 'As a general rule, then, automatic translations may be more likely to proceed from concrete forms of representation to abstract forms, rather than the reverse.”

Given that many aspects of conceptual metaphors can be explained by more general accounts of associative thought, the question is which unique predictions CMT provides. One of the most fundamental predictions of CMT is that experiential co-occurrences create primary metaphors (Lakoff \& Johnson, 1999). For example, because children are held affectionately by their parents, people are assumed to associate affection with warmth (Lakoff, 2012). We can imagine anecdotal support for this hypothesis, and future studies that examine how experiential co-occurrences create primary metaphors might (or might not) 
provide support for this hypothesis. However, there are reasons to doubt that experiential cooccurrence underlie all (or even most) primary metaphors.

For example, consider the primary metaphor 'bad is stinky' (Lakoff \& Johnson, 1999). Disgust is not present at birth. In the first years of life, children will put anything in their mouths, and Rozin and Fallon (1987) conclude that children's concept of disgust is very limited before eight years of age, with negative responses to odors such as sweat and feces emerging somewhere after five years of age. Furthermore, disgust reactions are learned, possibly through the facial expression of parents, and disgust responses vary across cultures. Whether smells are considered disgusting is extremely flexible even within individuals: The same smell is judged as disgusting when it is believed to originate from feces, but judged as pleasant when people believe it originates from cheese. In other words, despite the intuitive appeal that 'bad is stinky' emerges through a 'correlation between evaluative and olfactory experience’ (Lakoff \& Johnson, 1999), and notwithstanding the importance of experiential co-occurrence for learned associations, it leaves a lot to be desired as an explanation of the mechanisms underlying primary metaphors.

Social cognition is situated and context dependent (Barsalou, 1999; Mesquita, Barrett, \& Smith, 2010; Schwarz, 2007), and an important question in social priming research is how this context dependency can be explained (e.g., Bargh, 2006; Blair, 2002; Loersch \& Payne, 2011; this issue; Mitchell, Nosek, \& Banaji, 2003). Conceptual Metaphor Theory has a strong focus on universal ‘cognitive primitives’ (e.g., verticality, part-whole, balance, etc.), and these can be used to think about other concepts that we cannot understand directly. However, Conceptual Metaphor Theory does not allow for clear predictions about which neural mapping between concrete and abstract concepts will be activated depending on the situation, and is thus les equipped to inspire research on social inferences, which are inherently contextual. Furthermore, these cognitive primitives, which originate from work in cognitive 
linguistics, are not well-aligned with what are considered basic dimensions of meaning in the (social) psychological literature (e.g., valence and arousal, see Osgood, Suci, \& Tannenbaum, 1957). A more widely accepted viewpoint in social psychology assumes that people can directly activate psychological concepts such valence (e.g., Wyer \& Srull, 1986). An embodied theory of cognition that shares this assumption, and proposes that people partially simulate introspective states by re-activating neural systems that were also active when these introspective states were experiences, is Perceptual Symbol Systems theory (Barsalou, 1999), to which I will turn next.

\section{Perceptual Symbol Systems}

In addition to work on conceptual metaphors, perceptual symbol systems theory (PSS; Barsalou, 1999) has been very influential in recent work on social embodiment (for a review, see Niedenthal, Barsalou, Winkielman, Krauth-Gruber, \& Ric, 2005). The idea in perceptual theories of cognition is that both concrete and abstract conceptual processing is built upon and activates sensory-motor processes. These theories are a response to views of conceptual processing that argue for a purely symbolic language of thought (e.g., Fodor, 1975; Pylyshyn, 1984). According to proponents of amodal symbol systems, computations performed upon symbolic representations are the essence of mental processes. An important benefit of thought that relies on amodal symbols is that it can integrate different modal (e.g., haptic, visual, auditory) sources of information on an amodal symbolic level of representation.

A challenge for amodal symbol systems is how symbolic representations are connected to their referents, the objects in the world. This challenge is known as the symbol grounding problem (Harnad, 1990). Where do amodal symbols get their meaning from, if their only sources of meaning are other meaningless amodal symbols? Barsalou (1999) proposes a perceptual symbol system where conceptual knowledge consists of modal representations. These representations can be partially activated during language 
comprehension, leading to neural re-enactments (or simulations) that activate the same sensory and motor areas in our brain as were active when we directly experienced its referent. As opposed to conceptual metaphors, perceptual symbols are always context dependent, because they function as attractors in a connectionist network. Across different contexts, perceptual symbols can lead to different patterns of activation.

Perceptual symbol system theory has been embraced by emotion researchers. The idea that emotional responses have bodily components has a long history (e.g., Darwin, 1872), and there is a substantial amount of empirical data that suggests a bi-directional relationship between emotion processing and bodily states (for reviews, see Barrett \& Lindquist, 2008; Niedenthal, 2007). For example, Schwarz, Weinberger, \& Singer (1981) found that imagining specific emotional states changed the pattern of physiological activity in participants. In addition, the researchers found that physical activity (i.e., exercising) reduced the ability of participants to recreate as vividly as possible the feelings and physical sensations associated with states of sadness and relaxation. When it comes to emotion research, simulations that activate perceptual, motor, and introspective brain areas seem to have proven their worth. Modal simulations are often suggested to underlie embodied social inferences (e.g., Lee \& Schwarz, 2010; Meier, Hauser, Robinson, Friesen, \& Schjeldahl, 2007; Schneider, Rutjens, Jostmann, \& Lakens, 2011; Zhong \& Liljenquist, 2006). Traditionally, thoughts about religiousness, importance, social exclusion, or moral transgressions were not thought to depend upon physical experiences such as the temperature, motor activation, haptic experiences of weight, or vertical cues, but these recent studies suggest bodily experiences are closely related to higher cognitive processes. Providing unequivocal support for the idea that simulations are an essential part of social inferences is difficult, and there is a continuing debate about whether the activation of sensorimotor information simply 'enriches' conceptual processing, or is actually a necessary part of conceptual thought (see Barsalou, 2010; Mahon 
\& Caramazza, 2008; Zwaan, 2009). Resolving these different viewpoints is anything but straightforward. The scientific debate has gone on for at least 35 years, and some researchers have expressed doubts about the possibility that this debate will lead to scientific progress (Gomilla \& Calvo, 2008). Furthermore, the nature of mental representations might not be the most important research question for social cognition researchers.

It is widely acknowledged that not all conceptual thought is based on simulations, and that linguistic information is an efficient way to perform many cognitive tasks (e.g., Andrews, Vigliocco, \&Vinson, 2009; Barsalou, Santos, Simmons, \& Wilson, 2009; Louwerse, 2011). Therefore, an important question is in which situations people rely on concrete cues during social inference processes, instead of relying solely on linguistic information. This context challenge (see also Barsalou, 2009; Mesquita et al., 2010; Zwaan, 2009) is not a strange concept in experimental social psychology. The contextual nature of social information processing was raised as an especially important topic in research on implicit cognition (e.g., Blair, 2002; Loersch \& Payne, 2011; Mitchell, Nosek, \& Banaji, 2003; Schwarz, 2007), and the question which associations between concepts are salient depending on the context has been a central research question throughout the last 30 years of research on social priming (e.g., Bargh, 2006; Higgins, 1996; Smith, 1984).

Perceptual symbols are context dependent, and are easily integrated within situated views on cognition. Theoretical work on situated simulations provides many possibilities for social psychologists to examine contextualized social inferences (for a review, see Smith \& Collins, 2010). Because past research has focused on demonstrating that concrete cues can influence social inferences, the question when people actually use these cues has not been examined in detail. To summarize, the strong focus on situated simulations in perceptual theories of cognition provides a better fit with inherently contextualized views on cognition that are prevalent in social priming research than a 'metaphor-enriched' perspective on social 
cognition (e.g., Landau, Meier, \& Keefer, 2010). For social cognition researchers, a more fruitful approach for future research might be to leave the debate between modal vs. amodal representations to cognitive neuroscience, and instead focus on examining when the relationship between perceptual and conceptual information is salient and accessible enough to influence social inferences.

\section{One Step Back, Two Steps Forward?}

A critical look at recent studies that have examined whether concrete cues influence social inferences provides some reasons to doubt whether social embodiment research on social inferences has received the empirical or theoretical grounding that a progressive research line needs. Integrating social embodiment research more firmly with past theoretical work in social cognition might be one way to remedy this situation. In the following sections I will first describe Associated Systems Theory (Carlston, 1994), which is never used to explain social embodiment effects despite the fact that it is a dedicated theory of social concepts, and explicitly predicts interactions between perception, action, cognition, and affect. Then, I will revisit some of the central questions in early work on social inferences, and suggest that social embodiment researchers could address these questions in future research.

\section{Associated Systems Theory}

Associated Systems Theory (AST; Carlston, 1994) proposes that there are four primary mental systems that underlie representations: a visual/sensory system, a verbal/semantic system, an action system, and an affective system. It specifically tries to integrate different mental constructs into a single organized structure. Each system is hierarchically organized. At the lower level, these systems connect to highly specialized physical structures involved in perception, language, motoric behavior, and evaluation. At higher (more abstract) levels of cognition these systems interact in convergence zones (a 
similar idea is present in PSS theory) to create secondary hybrid representations which are referred to as categories, evaluations, behavioral observations, and orientations. These initial representations can be translated into secondary forms of representation through inferences. Carlston (1994, p. 35) reminds us that in addition to obvious inferences (e.g., inferring a person’s traits from their actions), ‘in principle, information in any form may be translated into any other form'. He refers to Wilson's (1968) studies where the status of a person can influence judgments about the perceived height of that individual (see also, Schubert, Schubert, \& Topolinski, 2013).

Carlston discusses the possibility that activation in a primary processing system might be able to 'warm up' that processing system and increase the likelihood that it will be used in subsequent tasks, but also notes it could interfere if the system has to be used for a second task before the first task is completed. As an example of a facilitation effect, he cites studies by Klatzky, Pellegrino, McCloskey, and Doherty (1989) that show how participants who are asked whether a particular action is plausible responded more quickly when they were primed by a hand shape than by a neutral signal. As an example of an interference effect, he mentions the studies by Engelkamp (1991) which revealed that sentences that were learned while making related movements (e.g., learning hammering a nail while making hammering movements) were less easily retrieved when participants had to make unrelated movements during retrieval. These studies are now often cited as examples of embodied cognition research, which highlights how social embodiment research can be effortlessly integrated with AST.

Niedenthal, Barsalou, Winkielman, Krauth-Gruber, and Ric (2005) discuss AST as a view related to perceptual symbol systems. They note that PSS is somewhat more radical about the modal nature of representations compared to AST, although as discussed earlier, providing unequivocal support for the nature of representations is a real challenge. 
Furthermore, PSS focusses more strongly on higher cognitive functions, such as the representation of abstract concepts (e.g., truth, democracy), or the type-token distinction between a concept and the objects that are instances of the concept. The differences between PSS and AST are not irreconcilable, and the two approaches are most likely complementary. PSS provides a more a detailed account of how people think about abstract concepts such as 'democracy' or 'truth', and how situated simulations influence cognition, whereas AST provides a more detailed explanation of the abstract concepts that are of focal interest to social cognition researchers (e.g., evaluations, orientations). PSS has actually faced some criticism because it explains how these abstract concepts are grounded through introspection, which is relatively poorly understood (Barsalou, 1999). Whether and how introspection contributes to the mental representation of concepts remains unclear, and AST provides a more straightforward explanation of how representations of abstract social concepts emerge through inferences. Thus, both PSS and AST have their own strengths, and social embodiment researchers should select the theoretical framework that is best suited for the questions they are trying to address.

AST (Carlston, 1994) provides a first formulation of a framework that, due to its integration of verbal, visual, behavioral, and affective representations, is perfectly suited to inspire researchers who aim to examine how concrete cues in the environment influence social inferences. In its current form, AST already provides an interesting theoretical departure point for researchers interested in the role of attention in social embodiment. The idea that different primary systems contribute to mental representations predicts that whenever attention is shifted to one of these systems, it will contribute more to the overall representation. Consider recent studies where positive and negative words are presented on the top and bottom of the screen, which shows that there is a bidirectional association between valence and vertical space (Santiago, Ouellet, Román, \& Valenzuela, 2012). Valence 
categorizations are influences by the vertical position of stimuli, and position categorizations are influenced by the valence of the stimuli, but only when the dimension irrelevant for the categorization was salient enough. It is surprising that social embodiment researchers have not embraced AST more enthusiastically in the last two decennia by attempting to develop it further, formally refine the theory, and adapt it based on recent insights. One possible reason is that the theoretical framework is presented in books and book chapters (e.g., Carlston, 1992, 1994) which are not as accessible as journal articles.

\section{Revisiting a Fundamental Question}

Although improving the theoretical grounding of social embodiment research that examines how concrete cues in the environment influence social inferences is an important starting point, it is equally important to ask the right empirical questions. If we want to understand when and how concrete information in the environment will function as a cue that influences person perception, moral judgments, pro-social decisions, attitudes, and behaviors, we need to understand the influence of sensorimotor information on the accessibility and salience of social information (cf. Higgins \& Eitam, this issue). In essence, this implies examining meaning making by specifying the structure of the context in which it emerges (Bruner, 1990). These questions are not new, but revisiting them in social embodiment research might provide an important way forward.

If concrete cues can influence social inferences relatively automatically, the association between a concrete cue (e.g., weight) and an abstract concept (e.g., importance) needs to exist either due to evolutionary predispositions, Hebbian learning through repeated co-occurrences, or inferences that have become proceduralized after extensive practice. A first step is to distinguish between these different alternatives (for each social embodiment effect that can be reliably observed in replication studies). Perhaps people have repeatedly inferred that thick and heavy books contain a lot of important information, while light books 
are typically less important (e.g., Schneider et al., 2011). Perhaps people have come to associate warmth with affection by being (passively) held by their parents (e.g., Bowlby, 1969). Perhaps people associative darkness with negativity because we have evolved to be diurnal animals (e.g., Lakens, Semin, \& Foroni, 2012). Depending on the assumptions about the origin of the relationship between physical cues and social inferences, researchers can make predictions about the accessibility of these associations, which should be more chronic in evolutionary predispositions, and more goal-dependent in extensively practices inferences (Smith, 1984).

One straightforward question is how often experiences need to co-occur to form long lasting associations in memory. Insights from evaluative conditioning might be interesting in this respect (Hofmann, De Houwer, Perugini, Baeyens, \& Crombez, 2010), such as the preliminary finding that evaluative conditioning effects are smaller in children, and evaluative conditioning effects are much greater if people are aware of the contingency between the conditioned and unconditioned stimulus. These findings speak against the idea that experiential co-occurrences create associations purely through bottom-up processes (as assumed in CMT and AST), and are more in line with simulators that rely on an integration of information through selective attention (PSS). More knowledge about how meaning is derived from experiential co-occurrences (even if they do not underlie all primary metaphors in CMT) can be gathered through developmental studies or experiments that involve learning tasks where stimuli are repeatedly presented. Researchers could examine how new associations between sensory information and social concepts are learned, or whether existing associations are flexible enough to be changed. If attentional factors indeed play a role in establishing associations through experiential co-occurrences, the question is which contextual factors direct attention to co-occurring stimuli, and which do not. 
A second important question is whether there are individual differences in the way, or the extent to which, people rely on concrete cues (Meier et al., 2012). Individual differences are not only expected to exist due to differences in past experiential co-occurrences. Carlston (1994) raises the possibility that people might differ in in the kind of representation (e.g., visual, verbal, affect, action) they rely on. When examining social embodiment effects, one logical prediction from AST (but not necessarily from CMT or PSS) is that inferences by people with higher sensitivity to bodily cues are especially influenced by concrete sensorimotor information. When proceduralized inferences underlie social embodiment effects (but not when they are caused by evolutionary predispositions), different contexts or goals could temporarily change the type of representations people rely on. For example, Louwerse and Jeuniaux (2010) examined when information processing makes use of perceptual simulations, and when it uses linguistic distributional information. They found that peoples response times depended more strongly on linguistic information when the task was to make semantic judgments for words, but that they relied more on perceptual information when they had to perform judgments about the spatial relationship of pictures. The nature of the task people perform will almost always be a defining factor of the context.

Following the basic idea in cognition that the mind selects and seeks structure in the world (e.g., Hastie \& Carlston, 1980), the structural similarity view (Murphy, 1996) is an alternative to CMT that proposes all concepts are directly represented, with metaphors reflecting the similarity of pre-existing conceptual structures, such as when people use structural features of spatial movement to think about time (Boroditsky, 2000). Conceptual thought does not only require that the meaning content of concepts is grounded, but, especially for social relational concepts, it also requires concepts to be structured (e.g., Lakens, Semin, \& Foroni, 2011; 2012). Important questions remain about when and why 
environmental structures are salient enough to be used as cues that influence social inferences.

There are many aspects from PSS and AST that can be used when examining contextual factors that influence the salience of concrete environmental cues and how they influence the accessibility of social information. The idea of simulators in PSS can inspire researchers to examine how people develop specific simulations of social situations or certain kinds of abstract concepts (such as democracy) in an inherently contextualized manner. AST allows researchers to derive predictions about how different primary systems might contribute to or interfere with mental representations, depending on attentional factors, individual differences, and the type of inference a person is making.

Furthermore, social embodiment research will show greater progress if researchers start to incorporate insights from other research areas that have addressed the context challenge. Especially social psychological work on evaluation has developed advanced models of dynamic and context dependent affective inferences (e.g., Gawronski, Rydell, Vervliet, \& DeHouwer, 2010; Klauer, Teige-Mocigemba, \& Spruyt, 2009). These theories can be used to derive theoretical predictions about when inferences that underlie the mental representation of social concepts are influenced by activity in systems used for perception, action, or emotion. At the same time, these theories have assumptions about how valence is mentally represented, either as dedicated valence counters (Klauer et al., 2009), or a retrieved pattern of associated concepts (Gawronski et al., 2010) and developing a better understanding of the mental representation of valence might prove to be an interesting empirical question for social embodiment researchers that can in turn inspire social psychological work on evaluation.

\section{Conclusion}


To turn social embodiment research into a progressive research line several challenges need to be met. Researchers need to acknowledge that practically all theories about cognition predict that cognition and perception interact. Progress can only be made by explaining how cognition depends on or is influenced by systems used for perception, action, or emotion. Existing theories of embodied cognition are either not detailed enough when it comes to the predictions they make (CMT), or have been used to examine questions about the nature of mental representations that might never be settled unequivocally (PSS). We lack a reliable empirical basis of social embodiment effects that have examined how concrete cues influence social inferences, which makes inductive inferences an unlikely source of progress. A better approach might be to try to derive hypotheses from theoretical work on the influence of sensorimotor information on the accessibility and salience of social information, which will allow us to test novel predictions about the context in which social cognition is embodied. 


\section{References}

Anderson, J. R. (1974). Retrieval of prepositional information from long-term memory. Cognitive Psychology, 6, 451-474.

Bargh, J. A. (2006). What have we been priming all these years? On the development, mechanisms, and ecology of nonconscious social behavior. European Journal of Social Psychology, 36(2), 147-168.

Barrett, L. F., \& Lindquist, K. (2008). The embodiment of emotion. Chapter in G. Semin \& E. Smith (Eds.). Embodied grounding: Social, cognitive, affective, and neuroscience approaches (p. 237-262). New York: Cambridge University Press.

Barsalou, L. W. (1999). Perceptual symbol systems. Behavioral and Brain Sciences, 22, 577660.

Barsalou, L.W. (2009). Simulation, situated conceptualization, and prediction. Philosophical Transactions of the Royal Society of London: Biological Sciences, 364, 1281-1289.

Barsalou, L. W. (2010). Grounded cognition: past, present, and future. Topics in Cognitive Science, 2, 716-724.

Barsalou, L. W., Niedenthal, P. M., Barbey, A. K., \& Ruppert, J. A. (2003). Social embodiment. Psychology of Learning and Motivation, 43, 43-92.

Barsalou, L. W., Santos, A., Simmons, W. K., \& Wilson, C. D. (2008). Language and simulation in conceptual processing. In M. de Vega, A. M. Glenberg, \& A. C. Graesser (Eds.), Symbols, embodiment, and meaning (pp. 245-283). Oxford: Oxford University Press.

Blair, I. V. (2002). The malleability of automatic stereotypes and prejudice. Personality and Social Psychology Review, 6(3), 242-261.

Bowlby, J. (1969). Attachment and loss: Vol. 1. Attachment. New York: Basic Books. 
Boroditsky, L. (2000). Metaphoric structuring: Understanding time through spatial metaphors. Cognition, 75, 1-28.

Brandt, M. J., IJzerman, H. \& Blanken, I. (2014). Does recalling moral behavior change the perception of brightness? A replication and meta-analysis of Banerjee, Chatterjee, and Sinha (2012). Social Psychology.

Bruner, J. S., Goodnow, J., \& Austin, G. A. (1956). A Study of Thinking. New York: Wiley.

Carlston, D. E. (1992). Impression formation and the modular mind: The associated systems theory. In L. L. Martin \& A. Tesser (Eds.), The construction of social judgments (pp. 301-341). Hillsdale, NJ: Lawrence Erlbaum Associates.

Carlston, D. E. (1994). Associated Systems Theory: A systematic approach to the cognitive representation of persons and events. In R. S. Wyer (Ed.), Advances in Social Cognition, Vol. 7: Associated Systems Theory (pp. 1-78). Hillsdale, NJ: Erlbaum.

Carlston, D. E. (2010). Models of implicit and explicit mental representation. Handbook of Implicit social cognition: measurement, theory, and applications, 38-61.

Darwin, C. (1872). The expression of the emotions in man and animals. John Murray.

Dijksterhuis, A., van Knippenberg, A., \& Holland, R. W. (2014). Evaluating behavior priming research: Three observations and a recommendation. Social Cognition.

Eder, A. B., \& Rothermund, K. (2008). When do motor behaviors (mis) match affective stimuli? An evaluative coding view of approach and avoidance reactions. Journal of Experimental Psychology: General, 137(2), 262-281.

Earp, B. D., Everett, J. A. C., Madva, E. N., \& Hamlin, J. K. (in press). Out, damned spot: Can the "Macbeth Effect" be replicated? Basic and Applied Social Psychology.

Engelkamp, J. (1991). Memory of action events: Some implications for memory theory and for imagery. In C. Cornoldi \& M.A. McDaniel (Eds.), Imagery and cognition (pp. 183-219). New York: Springer-Verlag. 
Fodor, J. A. (1975). The language of thought. Cambridge, MA: Harvard University Press.

Fodor, J. A. (1985). Précis of The Modularity of Mind. Behavioral and Brain Sciences, 8, 1 42.

Gawronski, B. Rydell, R. J., Vervliet, B., \& De Houwer, J. (2010). Generalization Versus Contextualization in Automatic Evaluation. Journal of Experimental Psychology: General, 139, 683-701. DOI: 10.1037/a0020315

Gibbs Jr, R. W. (2011). Evaluating conceptual metaphor theory. Discourse Processes, 48, 529-562.

Glenberg, A., de Vega, M., \& Graesser, A. C. (2008). Framing the debate. In M. de Vega, A. Glenberg, \& A. C. Graesser (Eds.), Symbols and embodiment: Debates on meaning and cognition (pp. 1-10). Oxford, UK: Oxford University Press.

Gomila, A., \& Calvo, F. (2008) Directions for an embodied cognitive science: towards an integrated approach. In F. Calvo \& A. Gomila (eds.) Handbook of Cognitive Science: An Embodied Approach (pp. 1-25), San Diego, US: Elsevier Publishers Limited.

Harnad, S. (1990). The symbol grounding problem. Physica D, 42, 335-346.

Hastie, R., \& Carlston, D. (1980).Theoretical issues in person memory. In R. Hastie et al. (Eds.), Person memory (pp.1-53). Hillsdale, NJ: Erlbaum.

Higgins, E. T., \& Eitam, B. (2014). Priming...Shmiming: It's about knowing when and why stimulated memory representations become active. Social Cognition.

Hofmann, W., De Houwer, J., Perugini, M., Baeyens, F., \& Crombez, G. (2010). Evaluative conditioning in humans: a meta-analysis. Psychological Bulletin, 136, 390.

Ioannidis, J. P. A. (2005). Why most published research findings are false. PLoS Medicine, 2, e124. doi:10.1371/journal.pmed.0020124. 
Johnson, D. J., Cheung, F., Donnellan, M. B. (2014). Does cleanliness influence moral judgments? A direct replication of Schnall, Benton, and Harvey (2008). Social Psychology.

Jostmann, N. B., Lakens, D., \& Schubert, T. W. (2009). Weight as an embodiment of importance. Psychological Science, 20, 1169-1174. DOI: 10.1111/j.14679280.2009.02426.x

Klatzky, R. L., Pellegrino, J. W., McCloskey, B. P., \& Doherty, S. (1989). Can you squeeze a tomato? The role of motor representations in semantic sensibility judgments. Journal of Memory and Language, 28, 56-77. DOI:10.1016/0749-596X(89)90028-4

Lakens, D. (2012). Polarity correspondence in metaphor congruency effects: Structural overlap predicts categorization times for bi-polar concepts presented in vertical space. Journal of Experimental Psychology: Learning, Memory, and Cognition, 38, 726-723. doi: 10.1037/a0024955.

Lakens, D. (2014). Effects of sensorimotor information on thoughts, attitudes, and behavior lack evidential value. Manuscript in preparation.

Lakens, D. \& Evers, E. (2014). Sailing from the seas of chaos into the corridor of stability: Practical recommendations to increase the informational value of studies. Perspectives on Psychological Science.

Lakens, D., Semin, G. R., \& Foroni, F. (2011). Why your highness needs the people: Comparing the absolute and relative representation of power in vertical space. Social Psychology, 42, 205-213. DOI: 10.1027/1864-9335/a000064

Lakens, D., Semin, G. R., \& Foroni, F. (2012). But for the bad, there would not be good: Grounding valence in brightness through structural similarity. Journal of Experiment Psychology: General, 141, 584-594 
Lakoff, G., \& Johnson, M. (1999). Philosophy in the flesh: The embodied mind and its challenge to Western thought. Chicago, IL: University of Chicago Press.

Lakoff, G. (2008). The neural theory of metaphor. In: R. W. Gibbs (Ed.), Cambridge handbook of metaphor and thought (pp. 17 - 38). Cambridge, MA, Cambridge University Press.

Lakoff, G. (2012). Explaining embodied cognition results. Topics in Cognitive Science, 4, 773-785.

Landau, M. J., Meier, B. P., \& Keefer, L. A. (2010). A metaphor-enriched social cognition. Psychological Bulletin, 136, 1045-1067.

LeBel, E. P., \& Campbell, L. (in press). Heightened sensitivity to temperature cues in highly anxiously attached individuals: Real or elusive phenomenon? Psychological Science.

LeBel, E. P., \& Wilbur, C. J. (in press). Big secrets do not necessarily cause hills to appear steeper. Psychonomic Bulletin \& Review.

Lee, S. W., \& Schwarz, N. (2010). Dirty hands and dirty mouths: Embodiment of the moralpurity metaphor is specific to the motor modality involved in moral transgression. Psychological Science, 21(10), 1423-1425.

Loersch, C., \& Payne, B. K. (2011). The situated inference model: An integrative account of the effects of primes on perception, behavior, and motivation. Perspectives on Psychological Science, 6(3), 234-252.

Loersch, C., \& Payne, B. K. (2014). Situated inference and the what, who, and where of priming. Social Cognition.

Louwerse, M. M. (2011). Symbol interdependency in symbolic and embodied cognition. Topics in Cognitive Science, 3(2), 273-302.

Louwerse, M. M., \& Jeuniaux, P. (2010). The linguistic and embodied nature of conceptual processing. Cognition, 114, 96-104. 
Lynott, D., Corker, K. S., Wortman, J., Connell, L., Donnellan, M. J., Lucas, R. E., \&, O'Brien, K. (2014). Replication of “Experiencing physical warmth promotes interpersonal warmth” by Williams \& Bargh (2008, Science). Social Psychology.

Mahon, B. Z., \& Caramazza, A. (2008). A critical look at the embodied cognition hypothesis and a new proposal for grounding conceptual content. Journal of Physiology-Paris, 102, 59-70.

McGlone, M.S. (2007). What is the explanatory value of a conceptual metaphor? Language \& Communication, 27, 109-126.

McGlone, M. S. (2011). Hyperbole, Homunculi, and Hindsight Bias: An Alternative Evaluation of Conceptual Metaphor Theory. Discourse Processes, 48, 563-574.

Meier, B. P., \& Robinson, M. D. (2004). Why the sunny side is up: Associations between affect and vertical position. Psychological Science, 15(4), 243-247.

Meier, B. P., Hauser, D. J., Robinson, M. D., Friesen, C. K., \& Schjeldahl, K. (2007). What's" up" with God? Vertical space as a representation of the divine. Journal of Personality and Social Psychology, 93(5), 699-710.

Meier, B. P., Schnall, S., Schwarz, N., \& Bargh, J. A. (2012). Embodiment in social psychology. Topics in Cognitive Science, 4, 705-716.

Mesquita, B. Barrett, L. F., \& Smith, E. R. (Eds.). (2010). The mind in context. New York, NY: Guilford.

Mitchell, J. P., Nosek, B. A., \& Banaji, M. R. (2003). Contextual variations in implicit evaluation. Journal of Experimental Psychology: General, 132(3), 455-469.

Molden, D. C. (2014). Understanding priming effects in social psychology: What is "social priming” and how does it occur? Social Cognition.

Murphy, G. L. (2004). The big book of concepts. Cambridge, MA: MIT Press.

Murphy, G. L. (1996). On metaphoric representation. Cognition, 60, 173-204. 
Niedenthal, P. M. (2007). Embodying emotion. Science, 316(5827), 1002-1005.

Niedenthal, P. M., Barsalou, L., Winkielman, P., Krauth-Gruber, S., \& Ric, F. (2005). Embodiment in attitudes, social perception, and emotion. Personality and Social Psychology Review, 9, 184-211.

Nosek, B. A., \& Lakens, D. (2014). Registered reports: A method to increase the credibility of published results. Social Psychology.

Osgood, C. E., Suci, G. J., \& Tannenbaum, P. H. (1957). The measurement of meaning. Urbana, IL: University of Illinois Press.

Pashler, H., Coburn, N., \& Harris, C. R. (2012). Priming of social distance? Failure to replicate effects on social and food judgments. PloS One, 7(8), e42510.

Platt, J. R. (1964). Strong inference. Science, 146(3642), 347-353.

Pylyshyn, Z. W. (1984). Computation and cognition. MIT Press.

Richards, I. A. (1936). The philosophy of rhetoric. Oxford, Oxford University Press.

Rotteveel, M., \& Phaf, R. H. (2004). Automatic affective evaluation does not automatically predispose for arm flexion and extension. Emotion, 4(2), 156-172.

Rozin, P., \& Fallon, A. E. (1987). A perspective on disgust. Psychological Review, 94, 23-41. DOI: 10.1037/0033-295X.94.1.23.

Salancik, G. R., \& Pfeffer, J. (1978). A social information processing approach to job attitudes and task design. Administrative Science Quarterly, 23, 224-253.

Santiago, J., Ouellet, M., Román, A., \& Valenzuela, J. (2012). Attentional factors in conceptual congruency. Cognitive Science, 36(6), 1051-1077.

Schneider, I. K., Rutjens, B., Jostmann, N. B., \& Lakens, D. (2011). Weighty matters: Importance literally feels heavy. Social Psychological and Personality Science, 2, 474-478. DOI: 10.1177/1948550610397895. 
Schubert, T. W. (2005). Your highness: Vertical positions as perceptual symbols of power. Journal of Personality and Social Psychology, 89(1), 1-21.

Schubert, L., Schubert, T. W., \& Topolinski, S. (2013). The effect of spatial elevation on respect depends on merit and medium. Social Psychology, 44, 147-159. DOI: 10.1027/1864-9335/a000134.

Schubert, T. W., Waldzus, S., \& Seibt, B. (2011). More than a metaphor: How the understanding of power is grounded in experience. In T. W. Schubert \& A. Maass (Eds), Spatial dimensions of social thought (pp. 153 - 185). Berlin: Mouton de Gruyter.

Schubert, T. W., \& Semin, G. R. (2009). Embodiment as a unifying perspective for psychology. European Journal of Social Psychology, 39(7), 1135-1141.

Schwarz, N. (2007). Attitude construction: Evaluation in context. Social Cognition, 25, 638656.

Simonsohn, U., Nelson, L., \& Simmons, J. (2013). P-curve: A key to the file drawer. Journal of Experimental Psychology: General.

Smith, E. R. (1984). Model of social inference processes. Psychological Review, 91(3), 392413.

Smith, E. R., \& Collins, E. C. (2010). Situated cognition. In B. Mesquita, L. F. Barrett, \& E. R. Smith (Eds.), The mind in context (pp. 126-145). New York: Guilford Press

Srull, T. K. ,\& Wyer, R. S. (1979). The role of category accessibility in the interpretation of information about persons: Some determinants and implications. Journal of Personality and Social Psychology, 37, 1660-1672

Strack, F., Martin, L. L., \& Stepper, S. (1988). Inhibiting and facilitating conditions of the human smile: A nonobtrusive test of the facial feedback hypothesis. Journal of Personality and Social Psychology, 54(5), 768-777. 
Wilson, P. R. (1968). Perceptual distortion of height as a function of ascribed academic status. Journal of Social Psychology, 74, 97-102.

Whitney, W. D. (1875). The life and growth of language: An outline of linguistic science. New York: Appleton.

Wyer, R. S. (1974). Cognitive organization and change: An information processing approach. Potomac, MD : Erlbaum.

Wyer, R. S., \& Srull, T. K. (1986). Human cognition in its social context. Psychological Review, 93, 322 -359. DOI: 10.1037/0033-295X.93.3.322.

Zhong, C. B., \& Liljenquist, K. (2006). Washing away your sins: Threatened morality and physical cleansing. Science, 313(5792), 1451-1452.

Zwaan, R. A. (2009). Mental simulation in language comprehension and social cognition. European Journal of Social Psychology, 39, 1142-1150. 